Exposure to famine in early life and the risk of obesity in adulthood in Qingdao : Evidence from the 1959-1961 Chinese famine

Liu, L.

2017-02

Liu , L , Pang , Z C , Sun , J P , Xue , B , Wang , S J , Ning , F \& Qiao , Q 2017 , ' Exposure to famine in early life and the risk of obesity in adulthood in Qingdao : Evidence from the 1959-1961 Chinese famine ' , Nutrition, Metabolism and Cardiovascular Diseases , vol. 27 , no. 2 , pp. 154-160 . https://doi.org/10.1016/j.numecd.2016.11.125

http://hdl.handle.net/10138/236598

https://doi.org/10.1016/j.numecd.2016.11.125

publishedVersion

Downloaded from Helda, University of Helsinki institutional repository.

This is an electronic reprint of the original article.

This reprint may differ from the original in pagination and typographic detail.

Please cite the original version. 


\title{
Exposure to famine in early life and the risk of obesity in adulthood in Qingdao: Evidence from the 1959-1961 Chinese famine
}

\author{
L. Liu $^{\mathrm{a}, \mathrm{b}}$, Z.C. Pang ${ }^{\mathrm{a}, \mathrm{b}, *}$, J.P. Sun ${ }^{\mathrm{b}}$, B. Xue ${ }^{\mathrm{b}}$, S.J. Wang ${ }^{\mathrm{b}}$, F. Ning ${ }^{\mathrm{b}}$, Q. Qiao ${ }^{\mathrm{c}}$ \\ ${ }^{a}$ Department of Nutrition and Food Hygiene, Qingdao University Medical College, Qingdao 266021, Shandong Province, China \\ ${ }^{b}$ Qingdao Municipal Center for Disease Control and Prevention, Qingdao 266033, Shandong Province, China \\ ${ }^{c}$ Department of Public Health, University of Helsinki, Helsinki 00014, Finland
}

Received 8 September 2016; received in revised form 26 November 2016; accepted 29 November 2016

Available online 5 December 2016

\section{KEYWORDS}

Famine exposure;

Obesity;

Early life;

Adulthood

\begin{abstract}
Background and aims: We aimed to evaluate the association between famine exposure during early life and obesity and obesity $y_{\max }$ (obese at the highest weight) in adulthood.

Methods and results: Data were from two population-based cross-sectional surveys conducted in 2006 and 2009 in Qingdao, China. A total of 8185 subjects born between 1/1/1941 and 12/31/ 1971 were categorized into unexposed (born between 01/01/1962 and 12/31/1971), fetal/infant exposed (born between 01/01/1959 and 12/31/1961), childhood exposed (born between 01/01/ 1949 and 12/31/1958) and adolescence exposed (born between 01/01/1941 and 12/31/1948) according to their age when exposed to the Chinese famine from 1959 to 1961. Obesity was defined as BMI (body mass index) $\geq 28.0$ and obesity $y_{\max }$ was defined as BMI $_{\max }$ (BMI at the highest weight $) \geq 28$.0. We compared fetal/infant exposed, childhood exposed and adolescence exposed to the unexposed using logistic regression models to assess the effect of famine exposure on later obesity and obesitymax. Fetal/infant exposed $(\mathrm{OR}=1.59, P<0.001)$, childhood exposed $(\mathrm{OR}=1.42, P<0.01)$ and adolescence exposed $(\mathrm{OR}=1.86, P<0.01)$ all had higher risks of obesity than the unexposed. Exposure groups were more likely to be obese at their highest weight than the unexposed, and ORs (95\%Cls) for obesity $\max _{\text {in }}$ in the fetal/infant exposed, childhood exposed and adolescence exposed were 1.49(1.20-1.86), 1.24(1.02-1.49) and 1.64 (1.40 $-1.93)$, respectively. Similar results were found in both men and women.

Conclusion: Exposure to famine in early life was associated with increased risks of obesity and obesity $_{\max }$ in adulthood. Preventing undernutrition in early life appears beneficial to reduce the prevalence of later obesity.

๑) 2016 The Italian Society of Diabetology, the Italian Society for the Study of Atherosclerosis, the Italian Society of Human Nutrition, and the Department of Clinical Medicine and Surgery, Federico II University. Published by Elsevier B.V. All rights reserved.
\end{abstract}

\section{Introduction}

Obesity is defined as abnormal or excessive fat accumulation that may impair health, and the most widely used index for mearing obesity is BMI [weight $(\mathrm{kg}) /$ height $\left(\mathrm{m}^{2}\right)$ ]. Obesity has become a global public health problem affecting all age groups and challenging all over the word. Global obesity prevalence increased dramatically over the

\footnotetext{
* Corresponding author. Qingdao University Medical College, Qingdao 266021, Shandong Province, China. Fax: +86 53285661020.

E-mail address: 15726227711@163.com (Z.C. Pang).
}

past four decades, from $3.2 \%$ in 1975 to $10.8 \%$ in 2014 in men, and from $6.4 \%$ to $14.9 \%$ in women [1]. Obesity can lead to hypertension, diabetes, stroke, musculoskeletal disorders, certain types of cancer, gallbladder disease, coronary heart disease, reduced life expectancy and higher all-cause mortality [2-5]. Though obesity could cause many other diseases, it is a kind of preventable disease in itself. Therefore, it is important to explore the etiology of obesity. Physical inactivity, genetic susceptibility, aging, dietary structure changes, smoking cessation, excess alcohol intake, a high maternal BMI before pregnancy and early menarche were all associated with obesity $[2,6-8]$. 
Besides, low birth weight $(<2,500 \mathrm{~g})$ was considered to be a risk factor of obesity in later life, indicating exposure to famine during early life might increase the risk of obesity in adulthood $[9,10]$.

Reports about the impact of early-life famine exposure on later obesity were not consistent. Most studies showed a positive relation between famine exposure and obesity in adult women but not in men [11-15], though one other study suggested famine exposure during the first half of pregnancy in men resulted in significantly higher obesity rate [16]. By contrast, a study of 12,065 adults and another study of 35,025 women born before, during or after Chinese famine found fetal/infant exposure to famine could reduce the risk of obesity in adulthood [11,17]. The negative relation was also observed during the last trimester of pregnancy and the first month of life in a Dutch study [16]. Additionally, a few studies demonstrated no relationship between famine exposure at some stages of early life and later obesity $[16,18,19]$. Besides, studies on the relationship between famine exposure during adolescence and later obesity were sparse and no study has reported the impact of famine exposure on the highest weight. Due to the limitations of previous studies, further studies to explore the association between famine exposure during early life and obesity in adult are in need.

The famine in China from 1959 to 1961, one of the most disastrous catastrophe in human history, led to more than 30 million deaths and 33 million fertility losses [20,21]. The famine roughly lasted for three years and therefore it was documented as "three-year natural disaster" in Chinese literatures. Shandong was one province that suffered the most severe famine in China [22]. In the present study, we used data from two population-based surveys in 2006 and 2009 in Qingdao city, Shandong province, China to evaluate the impact of famine exposure on risks of obesity and obesity $y_{\max }$ in adulthood.

\section{Methods}

\section{Subjects and design}

In 2006, a population-based cross-sectional study was conducted in Qingdao, China. A stratified, random cluster sampling method was adopted to recruit a representative sample in the general population. The survey was performed in three urban districts (Shinan, Shibei and Sifang) and three rural counties (Jiaonan, Huangdao and Jimo). Five resident communities from each district with 200-250 individuals living in Qingdao for at least 5 years from each community were randomly selected. A total of 6100 individuals aged 35-74 years were invited to participate in the survey and 5355 attended. Second cross-sectional survey with the same sampling, protocols, questionnaires, physical examination, and laboratory determination methods as 2006 survey was conducted in 2009 in Qingdao again. Subjects in 2006 and 2009 survey were not duplicate. A total of 5110 subjects attended the 2009 survey, with a response rate of $67.1 \%$. In the current study, we chose individuals born between $1 / 1 / 1941$ and 12/31/1971, and categorized them into four groups according to their age at exposure: fetal/infant exposed (born between 01/01/1959 and 12/31/1961), childhood exposed (born between 01/01/ 1949 and 12/31/1958), adolescence exposed (born between 01/01/1941 and 12/31/1948) and unexposed (born between $01 / 01 / 1962$ and 12/31/1971). After excluding individuals with missing or invalid data, 3109 men and 5076 women were included in the present data analysis.

The ethics committee of the Qingdao Hiser Hospital, the Qingdao Endocrine \& Diabetes Hospital and the Qingdao Municipal Center for Disease Control and Prevention (CDC) approved the studies. Informed written consent was obtained from each participant.

\section{Measurements and variables}

The subjects were interviewed to obtain information about their birthdate, gender, family monthly income, residence place, education, family history of disease, smoking and alcohol habits. Height and weight were measured with individuals wearing light clothes and without shoes. Height to the nearest $1 \mathrm{~mm}$ and weight to the nearest $100 \mathrm{~g}$ were measured. The participants were also asked to recall their highest weight from the past to survey. After at least a 15-min rest, three consecutive blood pressure (BP) readings from the right arm of seated individuals were recorded at least 30s apart, and the mean of the three readings was used for the analysis.

Blood samples were drawn from the antecubital vein into EDTA tubes containing sodium fluoride and centrifuged at the survey site. The specimens were placed in icecooled containers and transported immediately into the Qingdao Hiser Hospital in 2006 and Qingdao Endocrine \& Diabetes Hospital in 2009 for lab test. Biochemical variables included fasting plasma glucose (FPG), 2-h plasma glucose (2 hPG), fasting serum uric acid (UA), triglycerides (TG), total cholesterol (TC), high density lipoprotein cholesterol (HDL) and low density lipoprotein cholesterol (LDL).

Family history of obesity was defined as positive if at least one of the first degree relatives was obese. In the current study, we adopted Chinese criterion to define normal weight as BMI 18.5-23.9, overweight as BMI 24.0-27.9 and obesity as BMI $\geq 28.0$ [23]. Highest weight was used to calculate $\mathrm{BMI}_{\max }$. Overweight ${ }_{\max }$ (overweight at the highest weight) was defined as $B M I_{\max } 24.0-27.9$ and obesity $y_{\max }$ was defined as $\mathrm{BMI}_{\max } \geq 28.0$. Diabetes was defined as FPG $\geq 7.0 \mathrm{mmol} / \mathrm{L}$ and/or $2 \mathrm{hPG} \geq 11.1 \mathrm{mmol} / \mathrm{L}$ [24]. If a person met at least one of the following criteria:1) TC $\geq 5.72 \mathrm{mmol} / \mathrm{L} ; 2)$ TG $\geq 1.70 \mathrm{mmol} / \mathrm{L} ; 3) \mathrm{HDL}$ $<0.91 \mathrm{mmol} / \mathrm{L}$; 4) LDL $>3.64 \mathrm{mmol} / \mathrm{L}$, he or she was considered to have dyslipidemia [25].

\section{Statistical analysis}

For continuous variables, group differences were tested using a t-test or one-way analysis of variance (ANOVA) complemented by the LSD test. The $\chi^{2}$ test was employed to compare differences between groups for categorical variables. Data were reused in the comparison between 
males and females, and therefore the statistical significance level was adjusted using the Bonferroni correction equation to reduce the likelihood of type I errors [26]. Risks of overweight, obesity, overweight max $_{\text {ax }}$ and obesity max $_{\text {mamong }}$ fetal/infant, childhood and adolescence exposed compared with the unexposed were examined with the method of maximum likelihood by using binary logistic regression models. Analyses were adjusted for age, education, family history of obesity (positive/negative), family month income, residence place, current smoking (yes/no), current drinking (yes/no), hypertension (yes/no), diabetes (yes/no), dyslipidemia (yes/no) and UA, all assessed in 2006 and 2009 survey. Interaction between famine exposure and sex, residence place, education, family month income and family history of obesity on overweight, overweight ${ }_{\max }$, obesity and obesity $\max _{\max }$ was tested by adding multiplicative factors in the binary logistic regression models. Data were analyzed with SPSS version 17.0(SPSS, Chicago, IL).

\section{Results}

A total of 8185 subjects ( $62.01 \%$ women) were included in the current study, with a mean \pm standard deviation (SD) age of $49.85 \pm 8.65$ years. Of all subjects, 3411 subjects (41.67\%) were overweight and 1807 (22.10\%) were obese, and the prevalence of overweight $\mathrm{max}_{\max }$ and obesity $\max _{\max }$ was $45.40 \%$ and $30.30 \%$, respectively. $66.70 \%$ men and $59.80 \%$ women lived in rural areas, and men were more likely to be a smoker or alcohol user than women. Men had higher prevalence of hypertension, diabetes and dyslipidemia, and higher levels of SBP and TG. Mean values of BMI, $\mathrm{BMI}_{\max }, \mathrm{HDL}$ and LDL levels, and the prevalence of obesity and obesity max $_{\max }$ were all significantly higher in women than in men. Men and women did not differ in percentage of positive obesity family history, overweight prevalence, DBP, FPG, 2 hPG and TC levels (Table 1).

As shown in Table 2, average BMI ranged from $24.93 \mathrm{~kg} /$ $\mathrm{m}^{2}$ to $25.84 \mathrm{~kg} / \mathrm{m}^{2}$, and average $\mathrm{BMI}_{\max }$ varied between $25.86 \mathrm{~kg} / \mathrm{m}^{2}$ and $27.14 \mathrm{~kg} / \mathrm{m}^{2}$. In women, fetal/infant (25.20\%), childhood $(26.00 \%)$ and adolescence exposed (31.10\%) all had higher prevalence of obesity than the unexposed (17.10\%), and $23.90 \%$ of unexposed, $32.20 \%$ of fetal/infant exposed, $34.90 \%$ of childhood exposed and $43.40 \%$ of adolescence exposed were obese at their highest weight. Mean values of $\mathrm{BMI}_{\max }$ in fetal/infant exposed and adolescence exposed were significantly higher than that in

Table 1 General characteristics of subjects in 2006 and 2009 survey.

\begin{tabular}{|c|c|c|c|c|}
\hline & Total $(\mathrm{N}=8175)$ & Men $(\mathrm{N}=3109)$ & Women $(\mathrm{N}=5076)$ & $P$ value ${ }^{a}$ \\
\hline Age (years) & $49.85 \pm 8.65$ & $50.22 \pm 8.91$ & $49.62 \pm 8.48$ & $<0.001$ \\
\hline Residence place & & & & $<0.001$ \\
\hline Urban & 3079 (37.60) & $1036(33.30)$ & $2043(40.20)$ & \\
\hline Rural & $5106(62.40)$ & 2073 (66.70) & 3033 (59.80) & \\
\hline Education & & & & $<0.001$ \\
\hline Illiteracy & $812(9.90)$ & $124(4.00)$ & $688(13.50)$ & \\
\hline Primary & $1715(21.00)$ & $578(18.60)$ & $1137(22.40)$ & \\
\hline Secondary & $3092(37.80)$ & $1287(41.40)$ & 1805 (35.60) & \\
\hline Senior & $1741(21.30)$ & $677(21.80)$ & $1064(21.00)$ & \\
\hline University & 825 (10.10) & $443(14.20)$ & $382(7.5)$ & \\
\hline Family month income, $¥$ & & & & $<0.001$ \\
\hline$\leq 999$ & $5862(71.60)$ & $1866(60.00)$ & 3996 (78.70) & \\
\hline 1000-2999 & 2034 (24.90) & 1024 (32.90) & $1010(19.90)$ & \\
\hline$\geq 3000$ & $289(3.50)$ & $219(7.00)$ & $70(1.40)$ & \\
\hline Current smoking & $1784(21.80)$ & 1667 (53.70) & $117(2.30)$ & $<0.001$ \\
\hline Current drinking & $1470(18.00)$ & 1399 (45.00) & $71(1.40)$ & $<0.001$ \\
\hline Family history of obesity & $362(4.40)$ & $122(3.90)$ & $240(4.70)$ & 0.086 \\
\hline BMI $\left(\mathrm{kg} / \mathrm{m}^{2}\right)$ & $25.36 \pm 3.39$ & $25.20 \pm 3.27$ & $25.47 \pm 3.46$ & 0.001 \\
\hline Overweight & 3411 (41.67) & $1305(42.00)$ & $2106(41.50)$ & 0.665 \\
\hline Obesity & 1807 (22.10) & $627(20.20)$ & $1180(23.20)$ & 0.001 \\
\hline $\mathrm{BMI}_{\max }\left(\mathrm{kg} / \mathrm{m}^{2}\right)$ & $26.45 \pm 4.39$ & $26.24 \pm 3.87$ & $26.58 \pm 4.68$ & 0.001 \\
\hline Overweight $_{\max }$ & $3716(45.40)$ & $1461(47.00)$ & $2255(44.40)$ & 0.024 \\
\hline Obesity $_{\max }$ & $2483(30.30)$ & $872(28.00)$ & $1611(31.70)$ & $<0.001$ \\
\hline SBP (mmHg) & $132.79 \pm 21.32$ & $133.84 \pm 19.84$ & $132.16 \pm 22.16$ & $<0.001$ \\
\hline DBP (mmHg) & $84.17 \pm 12.09$ & $85.69 \pm 12.24$ & $83.24 \pm 11.90$ & 0.114 \\
\hline Hypertension & 3905 (47.70) & $1601(51.50)$ & $2304(45.40)$ & $<0.001$ \\
\hline $\mathrm{FPG}(\mathrm{mmol} / \mathrm{L})$ & $5.93 \pm 1.77$ & $5.99 \pm 1.77$ & $5.89 \pm 1.77$ & 0.096 \\
\hline $2 \mathrm{hPG}(\mathrm{mmol} / \mathrm{L})$ & $7.40 \pm 3.47$ & $7.24 \pm 3.58$ & $7.51 \pm 3.39$ & 0.003 \\
\hline Diabetes & 1210 (14.80) & 505 (16.20) & 705 (13.90) & 0.002 \\
\hline TC $(\mathrm{mmol} / \mathrm{L})$ & $5.28 \pm 1.04$ & $5.28 \pm 1.04$ & $5.28 \pm 1.04$ & 0.156 \\
\hline TG (mmol/L) & $1.43 \pm 1.21$ & $1.54 \pm 1.48$ & $1.36 \pm 1.01$ & $<0.001$ \\
\hline $\mathrm{HDL}(\mathrm{mmol} / \mathrm{L})$ & $1.64 \pm 0.43$ & $1.62 \pm 0.44$ & $1.65 \pm 0.43$ & $<0.001$ \\
\hline $\mathrm{LDL}(\mathrm{mmol} / \mathrm{L})$ & $3.12 \pm 1.19$ & $3.09 \pm 1.18$ & $3.14 \pm 1.21$ & $<0.001$ \\
\hline Dyslipidemia & 3363 (41.10) & 1357 (43.60) & 2006 (39.50) & $<0.001$ \\
\hline $\mathrm{UA}(\mu \mathrm{mol} / \mathrm{L})$ & $305.86 \pm 83.73$ & $353.12 \pm 84.49$ & $276.39 \pm 68.34$ & $<0.001$ \\
\hline
\end{tabular}

Data are presented as mean \pm SD for continuous variables, and $\mathrm{n}(\%)$ for categorical variables.

a $P$ values in $t$ test for difference in means or $\chi^{2}$ test for difference in proportions between men and women. 
Table 2 Characteristics of subjects in 2006 and 2009 survey by age of exposure at famine.

\begin{tabular}{|c|c|c|c|c|c|}
\hline & Unexposed & Fetal/infant exposed & Childhood exposed & Adolescence exposed & $P$ value $^{a}$ \\
\hline \multicolumn{6}{|l|}{ Total } \\
\hline Age (years) & $41.30 \pm 3.60$ & $47.14 \pm 2.16^{\mathrm{b}}$ & $53.28 \pm 3.59^{\mathrm{b}}$ & $62.72 \pm 3.12^{\mathrm{b}}$ & $<0.001$ \\
\hline $\operatorname{BMI}\left(\mathrm{kg} / \mathrm{m}^{2}\right)$ & $24.93 \pm 3.27$ & $25.48 \pm 3.36^{\mathrm{b}}$ & $25.60 \pm 3.39^{b}$ & $25.84 \pm 3.55^{\mathrm{b}}$ & $<0.001$ \\
\hline Overweight & 1266 (39.70) & $275(43.17)$ & $1236(42.87)^{\mathrm{c}}$ & $634(42.87)^{\mathrm{c}}$ & 0.011 \\
\hline Obesity & 598 (18.77) & $161(25.30)^{c}$ & $671(23.27)^{\mathrm{c}}$ & $377(25.49)^{c}$ & $<0.001$ \\
\hline $\mathrm{BMI}_{\max }\left(\mathrm{kg} / \mathrm{m}^{2}\right)$ & $25.86 \pm 4.04$ & $26.56 \pm 4.60^{\mathrm{b}}$ & $26.73 \pm 4.55^{\mathrm{b}}$ & $27.14 \pm 4.58^{b}$ & $<0.001$ \\
\hline Overweight $_{\max }$ & $1418(44.50)$ & $285(44.74)$ & $1343(46.58)$ & $670(45.30)$ & 0.428 \\
\hline Obesity $_{\max }$ & $803(25.20)$ & $212(33.28)^{c}$ & $922(31.98)^{c}$ & $546(36.90)^{c}$ & $<0.001$ \\
\hline \multicolumn{6}{|l|}{ Men } \\
\hline Age (years) & $41.20 \pm 3.54$ & $46.94 \pm 2.11^{\mathrm{b}}$ & $53.26 \pm 3.60^{\mathrm{b}}$ & $62.84 \pm 3.09^{b}$ & $<0.001$ \\
\hline $\operatorname{BMI}\left(\mathrm{kg} / \mathrm{m}^{2}\right)$ & $25.22 \pm 3.26$ & $25.56 \pm 3.44$ & $25.13 \pm 3.19$ & $25.17 \pm 3.36$ & 0.309 \\
\hline Overweight & $468(39.90)$ & $97(40.40)$ & $451(43.20)$ & $289(44.50)$ & 0.200 \\
\hline Obesity & $254(21.60)$ & $61(25.40)$ & $193(18.50)$ & $119(18.30)$ & 0.030 \\
\hline $\mathrm{BMI}_{\max }\left(\mathrm{kg} / \mathrm{m}^{2}\right)$ & $26.03 \pm 3.69$ & $26.61 \pm 4.23^{b}$ & $26.26 \pm 3.98$ & $26.46 \pm 3.86^{b}$ & 0.049 \\
\hline Overweight $_{\max }$ & $533(45.40)$ & $101(42.10)$ & $501(47.90)$ & $326(50.20)$ & 0.090 \\
\hline Obesity $_{\max }$ & $322(27.40)$ & $84(35.00)$ & $280(26.80)$ & $186(28.60)$ & 0.076 \\
\hline \multicolumn{6}{|l|}{ Women } \\
\hline Age (years) & $41.36 \pm 3.64$ & $47.27 \pm 2.18^{\mathrm{b}}$ & $53.29 \pm 3.59^{b}$ & $62.62 \pm 31.36^{\mathrm{b}}$ & $<0.001$ \\
\hline $\operatorname{BMI}\left(\mathrm{kg} / \mathrm{m}^{2}\right)$ & $24.76 \pm 3.27$ & $25.43 \pm 3.32^{\mathrm{b}}$ & $25.87 \pm 3.48^{\mathrm{b}}$ & $26.36 \pm 3.61^{\mathrm{b}}$ & $<0.001$ \\
\hline Overweight & 798 (39.70) & $178(44.80)$ & $785(42.70)$ & 345 (41.60) & 0.125 \\
\hline Obesity & $344(17.10)$ & $100(25.20)^{\mathrm{c}}$ & $478(26.00)^{c}$ & $258(31.10)^{\mathrm{c}}$ & $<0.001$ \\
\hline $\mathrm{BMI}_{\max }\left(\mathrm{kg} / \mathrm{m}^{2}\right)$ & $25.76 \pm 4.23$ & $26.53 \pm 4.82^{\mathrm{b}}$ & $26.99 \pm 4.82^{\mathrm{b}}$ & $27.68 \pm 5.01^{b}$ & $<0.001$ \\
\hline Overweight $_{\max }$ & $885(44.00)$ & $184(46.30)$ & $842(45.80)$ & $344(41.50)$ & 0.168 \\
\hline Obesity $\max$ & $481(23.90)$ & $128(32.20)^{c}$ & $642(34.90)^{c}$ & $360(43.40)^{c}$ & $<0.001$ \\
\hline
\end{tabular}

the unexposed in men. There were no significant differences between exposed and unexposed in the prevalence of overweight and overweight $\max _{\max }$ either in men or in women.

The crude ORs (95\%Cls) of obesity in fetal/infant, childhood and adolescence exposed were 1.46(1.20-1.79), 1.31(1.16-1.49) and $1.48(1.28-1.71)$, and corresponding ORs (95\%CIs) were $1.59(1.24-2.03), 1.42(1.11-1.82)$ and 1.86 (1.25-2.77), respectively, after adjusting for potential confounders. Fetal/infant, childhood and adolescence exposed all had higher risks to be obese at their highest weight than the unexposed. The ORs (95\%Cls) for obesity $y_{\max }$ were $1.48(1.23-1.78), 1.39(1.25-1.56)$ and 1.74 (1.52-1.98), to $1.49(1.20-1.86), 1.24(1.02-1.49)$ and 1.64 (1.40-1.93) after adjusting for potential confounders. Exposure to famine in fetal/infant, childhood and adolescence exposed did not increase risks for overweight and overweight $_{\max }$ in later life. Analyses stratified by gender were also performed and showed similar results as the total (Table 3). No significant interaction was found between famine exposure and sex, residence place, education, family month income and family history of obesity on overweight, overweight $_{\max }$, obesity and obesity $\max _{\max }$ (data not shown).

\section{Discussion}

In the present study with a large sample of Chinese adults, we found famine exposure in early life was associated with increased risks of obesity and obesity max $_{\text {max }}$ in adult men and women. No significant association was observed between famine exposure and overweight and overweight $\max _{\max }$ either in men or women. To our knowledge, this is the first study to evaluate the impact of famine exposure on obesity $\max$.

One Dutch study reported that obesity rate was lower for men with famine exposure during the last trimester of pregnancy and the first months of life, but higher in men with famine exposure in the first half of gestation [16]. Two other Dutch studies suggested that famine exposure may lead to increased adiposity in later life in females but not in males [14,15], but the Leningard study did not find any association between famine exposure and obesity [18]. Furthermore, a study about Biafran famine revealed that neither childhood nor fetal/infancy exposure to famine was related to obesity in adult, though fetal/infant exposed was associated with an increased risk of overweight [19]. Inconsistent with the above studies, fetal/infant exposed, childhood exposed and adolescence exposed were all linked to obesity in adult men and women in our study. The discrepancy might be caused by differences on the criterion for obesity, the severity and duration of famine, the grouping of exposure, age range, ethnicity and environment changes after famine exposure.

Analyzing the data of 35,025 women born in 1957-1963 in China, Huang et al. found BMI increased by $0.92 \mathrm{~kg} / \mathrm{m}^{2}$ in the 1957 cohort, and decreased by $0.3 \mathrm{~kg} / \mathrm{m}^{2}$ in the 1960 and 1961 cohorts. These significant effects on BMI were found only in rural cohorts but not for any of the urban cohorts [11]. However, after adjusting for age, sex, education, family history of obesity, family month income, current smoking, current drinking, hypertension, diabetes, dyslipidemia and UA, our study showed significant 
Table 3 The results of famine exposure during early life and obesity in adulthood.

\begin{tabular}{|c|c|c|c|c|}
\hline & Unexposed & Fetal/infant exposed & Childhood exposed & Adolescence exposed \\
\hline \multicolumn{5}{|l|}{ Total } \\
\hline \multicolumn{5}{|l|}{ Overweight } \\
\hline Crude OR (95\%CI) & Ref. & $1.15(0.97-1.37)$ & $1.14(1.03-1.26)$ & $1.14(1.01-1.29)$ \\
\hline$P$ value & & 0.107 & 0.013 & 0.043 \\
\hline Adjusted OR (95\%CI) & Ref. & $1.10(0.90-1.34)$ & $1.08(0.89-1.32)$ & $1.04(0.75-1.43)$ \\
\hline$P$ value & & 0.373 & 0.433 & 0.826 \\
\hline \multicolumn{5}{|l|}{ Obesity } \\
\hline Crude OR (95\%CI) & Ref. & $1.46(1.20-1.79)$ & $1.31(1.16-1.49)$ & $1.48(1.28-1.71)$ \\
\hline$P$ value & & $<0.001$ & $<0.001$ & $<0.001$ \\
\hline Adjusted OR (95\%CI) & Ref. & $1.59(1.24-2.03)$ & $1.42(1.11-1.82)$ & $1.86(1.25-2.77)$ \\
\hline$P$ value & & $<0.001$ & 0.005 & 0.002 \\
\hline \multicolumn{5}{|l|}{ Overweight $_{\max }$} \\
\hline Crude OR $(95 \% \mathrm{CI})$ & Ref. & $1.01(0.85-1.20)$ & $1.09(0.98-1.20)$ & $1.03(0.91-1.17)$ \\
\hline$P$ value & & 0.914 & 0.105 & 0.612 \\
\hline Adjusted OR (95\%CI) & Ref. & $0.96(0.79-1.17)$ & $0.98(0.80-1.19)$ & $0.82(0.60-1.13)$ \\
\hline$P$ value & & 0.688 & 0.821 & 0.235 \\
\hline \multicolumn{5}{|l|}{ Obesity $_{\max }$} \\
\hline Crude OR (95\%CI) & Ref. & $1.48(1.23-1.78)$ & $1.39(1.25-1.56)$ & $1.74(1.52-1.98)$ \\
\hline$P$ value & & $<0.001$ & $<0.001$ & $<0.001$ \\
\hline Adjusted OR (95\%CI) & Ref. & $1.49(1.20-1.86)$ & $1.24(1.02-1.49)$ & $1.64(1.40-1.93)$ \\
\hline$P$ value & & $<0.001$ & 0.027 & $<0.001$ \\
\hline \multicolumn{5}{|l|}{ Men } \\
\hline \multicolumn{5}{|l|}{ Overweight } \\
\hline Crude OR (95\%CI) & Ref. & $1.02(0.77-1.36)$ & $1.14(0.97-1.36)$ & $1.21(0.99-1.47)$ \\
\hline$P$ value & & 0.873 & 0.116 & 0.056 \\
\hline Adjusted OR (95\%CI) & Ref. & $1.01(0.72-1.39)$ & $1.31(0.94-1.82)$ & $1.48(0.87-2.50)$ \\
\hline$P$ value & & 0.994 & 0.105 & 0.149 \\
\hline \multicolumn{5}{|l|}{ Obesity } \\
\hline Crude OR $(95 \% \mathrm{CI})$ & Ref. & $1.23(0.89-1.70)$ & $0.82(0.67-1.01)$ & $0.81(0.64-1.03)$ \\
\hline$P$ value & & 0.200 & 0.064 & 0.092 \\
\hline Adjusted OR (95\%CI) & Ref. & $1.71(1.15-2.54)$ & $1.64(1.08-2.49)$ & $2.52(1.28-4.97)$ \\
\hline$P$ value & & 0.005 & 0.023 & 0.008 \\
\hline \multicolumn{5}{|l|}{ Overweight $_{\max }$} \\
\hline Crude OR $(95 \% \mathrm{CI})$ & Ref. & $0.87(0.66-1.16)$ & $1.11(0.94-1.31)$ & $1.21(0.99-1.47)$ \\
\hline$P$ value & & 0.347 & 0.231 & 0.052 \\
\hline Adjusted OR (95\%CI) & Ref. & $0.80(0.58-1.10)$ & $0.94(0.68-1.29)$ & $0.88(0.53-1.48)$ \\
\hline$P$ value & & 0.171 & 0.707 & 0.636 \\
\hline \multicolumn{5}{|l|}{ Obesity $_{\max }$} \\
\hline Crude OR (95\%CI) & Ref. & $1.42(1.06-1.91)$ & $0.97(0.80-1.17)$ & $1.06(0.86-1.31)$ \\
\hline$P$ value & & 0.019 & 0.738 & 0.588 \\
\hline Adjusted OR (95\%CI) & & $1.66(1.16-2.39)$ & $1.47(1.01-2.14)$ & $2.03(1.11-3.73)$ \\
\hline$P$ value & Ref. & 0.006 & 0.044 & 0.022 \\
\hline \multicolumn{5}{|l|}{ Women } \\
\hline \multicolumn{5}{|l|}{ Overweight } \\
\hline Crude OR (95\%CI) & Ref. & $1.24(0.99-1.54)$ & $1.13(0.99-1.29)$ & $1.08(0.92-1.28)$ \\
\hline$P$ value & & 0.055 & 0.055 & 0.055 \\
\hline Adjusted OR (95\%CI) & Ref. & $1.13(0.87-1.46)$ & $0.96(0.75-1.23)$ & $0.82(0.54-1.23)$ \\
\hline$P$ value & & 0.368 & 0.761 & 0.331 \\
\hline \multicolumn{5}{|l|}{ Obesity } \\
\hline Crude OR (95\%CI) & Ref. & $1.63(1.27-2.11)$ & $1.70(1.46-1.99)$ & $2.19(1.82-2.64)$ \\
\hline$P$ value & & $<0.001$ & $<0.001$ & $<0.001$ \\
\hline Adjusted OR (95\%CI) & Ref. & $1.56(1.14-2.14)$ & $1.41(1.04-1.92)$ & $1.76(1.07-2.89)$ \\
\hline$P$ value & & 0.005 & 0.027 & 0.025 \\
\hline \multicolumn{5}{|l|}{ Overweight $_{\max }$} \\
\hline Crude OR (95\%CI) & Ref. & $1.10(0.89-1.36)$ & $1.08(0.95-1.22)$ & $0.90(0.77-1.06)$ \\
\hline$P$ value & & 0.387 & 0.256 & 0.223 \\
\hline Adjusted OR (95\%CI) & Ref. & $1.07(0.83-1.38)$ & $0.99(0.78-1.27)$ & $0.77(0.51-1.15)$ \\
\hline$P$ value & & 0.598 & 0.966 & 0.203 \\
\hline \multicolumn{5}{|l|}{ Obesity $_{\max }$} \\
\hline Crude OR $(95 \% \mathrm{CI})$ & Ref. & $1.28(1.01-1.63)$ & $1.71(1.48-1.97)$ & $2.44(2.06-2.90)$ \\
\hline$P$ value & & 0.043 & $<0.001$ & $<0.001$ \\
\hline Adjusted OR (95\%CI) & Ref. & $1.37(1.05-1.78)$ & $1.44(1.11-1.87)$ & $1.81(1.19-2.76)$ \\
\hline$P$ value & & 0.020 & 0.005 & 0.006 \\
\hline
\end{tabular}


associations between early-life famine exposure and obesity and obesity max $_{\text {in }}$ in both urban and rural areas (Table S1). Huang's subjects were all women and relatively young, which may be the reason resulting in discrepancy of our results. Another Chinese study reported that famine exposure was related to increased risks of overweight and obesity in women but not men [12]. This study only adjusted for geographic areas and subjects were all rural residents. A third Chinese study whose subjects came from routine health checkup suggested only toddler group had higher risk of obesity in females [13]. Selective bias might lead to underestimation of the effect of famine exposure on obesity. Furthermore, the third study did not adjust for any potential confounder. Wang's study demonstrated a negative relation between famine exposure during both fetal development and infancy group and obesity in males [17]. Data of this study came from Nanhai and Zhongshan municipalities, Guangdong province, China, and our study adopted data from Qingdao city, Shandong province, China. During the Chinese famine, Guangdong province was considered a "less severely" affected region while Shandong was one province that suffered the most severe famine. Additionally, different exposure classification may be another reason contributing to the inconsistency.

The mechanisms for famine exposure and obesity risk are still not clear. The "fetal origin of adult disease (FOAD)" hypothesis proposed that undernutrition during critical periods of early development could induce changes of some organs. These transitions were beneficial in short term but might be at the expense of other tissues, thus predisposing individuals to metabolic and endocrine diseases in adulthood [27]. Another probable mechanism was that nutritional deprivation in early life affected the differentiation of hypothalamic centers regulating appetite and growth or caused hypothalamic dysfunction, which was related to obesity in adulthood. The "fat cell" theory of obesity was also put forward to explain the relationship between undernutrition and obesity. This theory suggested that the initial abnormality was in the fat cell itself precipitated by undernutrition in early life and later overfeeding, or by a genetic alteration in proteins involved in lipid metabolism. These abnormalities could lead to excessive fat deposition of body [28]. Furthermore, hypertension, diabetes and coronary heart disease were all associated with early-life undernutrition, indicating a relation between famine exposure and obesity in adulthood [14]. In animal experiments, rats experiencing deprivation of food during early life caused inappropriate hyperphagia from weaning until puberty, post-puberty and mature adulthood. These rats also had significantly higher level of fasting leptin. Hypercaloric nutrition intensified the metabolic abnormalities induced by undernutrition, including hyperinsulinism, hyperleptinemia, hypertension and obesity [29].

The strengths of the present study were as follows. First, a stratified, random cluster sampling method was adopted to recruit a representative sample of the general population from both rural and urban residents. Secondly, the impact of adolescence exposed on later obesity was analyzed in this present study. Thirdly, the association between famine exposure and the highest weight was analyzed for the first time. In addition, our study adjusted for enough potential confounders to reduce the effect of confounding factors on obesity.

However, some limitations should be noticed. First, Chinese famine affected all over the country and no area was not swept by the disaster, therefore, subjects had to be classified into different groups according to their birthdate instead of place of residence. Second, the prevalence of obesity did not increase with age all the time [30], but age might influence the result of adolescence exposed because the difference of age between adolescence exposed and the unexposed was relatively large. Third, because the response rate on birth weight was too low, the relation between birth weight and obesity in adulthood could not be analyzed. Lastly, the present study was cross-sectional.

In conclusion, our study showed that famine exposure in early life could increase risks of obesity and obesity max $_{\text {m }}$ in adult men and women. Thereby, measures should be taken to prevent undernutrition during pregnancy, infancy, childhood and adolescence to reduce the prevalence of obesity. Since obesity is associated with hypertension, diabetes and other metabolic disorders, improving earlylife nutrition should be given high priority to limit the increase of chronic non-communicable diseases.

\section{Funding}

This work was supported by grants from the World Diabetes Foundation [WDF05-108 \& 07-308].

\section{Conflict of interest}

The authors declared no conflict of interest.

\section{Acknowledgements}

We thank all the participants and team members who took part in the two surveys. We are grateful to the Qingdao Municipal Health Bureau and Qingdao Municipal Center for Disease Control and Prevention for their contribution to the field survey. The study was part of the Qingdao Diabetes Prevention Project funded by the World Diabetes Foundation (WDF05-108 \& 07-308). We also owe thanks to the Bayer and Lifescan Healthcare in China for the unrestricted grants in supporting the surveys.

\section{Appendix A. Supplementary data}

Supplementary data related to this article can be found at http://dx.doi.org/10.1016/j.numecd.2016.11.125.

\section{References}

[1] (NCD-RisC) NRFC. Trends in adult body-mass index in 200 countries from 1975 to 2014: a pooled analysis of 1698 population- 
based measurement studies with 19.2 million participants. Lancet 2016;387:1377-96.

[2] Organization WH. Obesity: preventing and managing the global epidemic. Report of a WHO consultation. i-xii vol. 894. World Health Organization technical report series; 2000. p. 1-253.

[3] Ni Mhurchu C, Rodgers A, Pan WH, Gu DF, Woodward M. Asia Pacific Cohort Studies C. Body mass index and cardiovascular disease in the Asia-Pacific Region: an overview of 33 cohorts involving 310000 participants. Int J Epidemiol 2004;33: $751-8$.

[4] Flegal KM, Kit BK, Orpana H, Graubard BI. Association of all-cause mortality with overweight and obesity using standard body mass index categories: a systematic review and meta-analysis. JAMA 2013;309:71-82.

[5] Garrow JS. Importance of obesity. BMJ 1991;303:704-6.

[6] Laitinen J, Power C, Jarvelin M. Family social class, maternal body mass index, childhood body mass index, and age at menarche as predictors of adult obesity. Am J Clin Nutr 2001;74:287-94.

[7] Kelishadi R, Alikhani S, Delavari A, Alaedini F, Safaie A, Hojatzadeh E. Obesity and associated lifestyle behaviours in Iran: findings from the first national non-communicable disease risk factor surveillance survey. Public Health Nutr 2008;11:246.

[8] Foulds HJA, Bredin SSD, Warburton DER. The prevalence of overweight and obesity in British Columbian Aboriginal adults. Obes Rev 2011;12.

[9] Newby PK, Dickman PW, Adami HO, Wolk A. Early anthropometric measures and reproductive factors as predictors of body mass index and obesity among older women. Int J Obes 2005;29: 1084-92.

[10] Minooee S, Ramezani Tehrani F, Mirmiran P, Azizi F. Low birth weight may increase body fat mass in adult women with polycystic ovarian syndrome. Int J Reproductive Biomed (Yazd, Iran) 2016;14:335-40.

[11] Huang C, Li Z, Wang M, Martorell R. Early life exposure to the 1959-1961 Chinese famine has long-term health consequences. J Nutr 2010;140:1874-8.

[12] Yang Z, Zhao WH, Zhang X, Mu R, Zhai Y, Kong L, et al. Impact of famine during pregnancy and infancy on health in adulthood. Obes Rev 2008;95.

[13] Wang Y, Wang X, Kong Y, Zhang JH, Zeng Q. The great chinese famine leads to shorter and overweight females in chongqing chinese population after 50 years. Obesity 2010;18:588.

[14] Stein AD, Kahn HS, Rundle A, Zybert P, De Bruin KVDP, Lumey LH. Anthropometric measures in middle age after exposure to famine during gestation: evidence from the Dutch famine. Am J Clin Nutr 2007;85:869-76
[15] Ravelli ACJ, Der Meulen JV, Osmond C, Barker DJP, Bleker OP. Obesity at the age of $50 \mathrm{y}$ in men and women exposed to famine prenatally. Am J Clin Nutr 1999;70:811-6.

[16] Ravelli G, Stein Z, Susser M. Obesity in young men after famine exposure in utero and early infancy. N. Engl J Med 2009;295:349.

[17] Wang P, Wang J, Lei Y, Xiao L, Luo Z. Impact of fetal and infant exposure to the Chinese great famine on the risk of hypertension in adulthood. PloS One 2012;7.

[18] Stanner S, Bulmer K, Andres C, Lantseva OE, Borodina VI, Poteen VV, et al. Does malnutrition in utero determine diabetes and coronary heart disease in adulthood? Results from the Leningrad siege study, a cross sectional study. BMJ 1997;315:1342.

[19] Hult M, Tornhammar P, Ueda P, Chima C, Bonamy AE, Ozumba BC, et al. Hypertension, diabetes and overweight: looming legacies of the biafran famine. PloS One 2010;5.

[20] Smil V. China's great famine: 40 years later. BMJ 1999;319: 1619-21.

[21] Luo Z, Mu R, Zhang X. Famine and overweight in China. Appl Econ Perspect Policy 2006;28:296-304.

[22] China NBoSo. Ministry of civil affairs of the People's Republic of China. Chinese Report on famine from 1949 to 1995. Beijing: Chinese Statistics Publishing House; 1995.

[23] Council of Disease Control HMPRC. Guideline for prevention and Control of overweight and obesity in chinese adults. Beijing: Peoples Medical Publishing House; 2006.

[24] Consultation W. Definition, diagnosis and classification of diabetes mellitus and its complications. Part 1: diagnosis and classification of diabetes mellitus. Geneva: World Health Organization; 1999 (WHO/NCD/NCS/99.2).

[25] Chinese cardiology journal editorial board for dyslipidemia countermeasures task force. Recommendations for dyslipidemia prevention. Chin Cardiol J 1997;25:169-73.

[26] Abdi H. Bonferroni and Sidak corrections for multiple comparisons. In: Salkind NJ, editor. Encyclopedia of measurements and statistics. Thousand Oaks, California: Sage; 2007.

[27] Khanna SB, Dash K, Swasti KD. Fetal origin of adult disease. JK Sci 2007:9:206-10.

[28] Proietto J, Thorburn AW. Animal models of obesity-theories of aetiology. Bailliere's Clin Endocrinol metabolism 1994;8:509-25.

[29] Vickers MH, Breier BH, Cutfield WS, Hofman PL, Gluckman PD. Fetal origins of hyperphagia, obesity, and hypertension and postnatal amplification by hypercaloric nutrition. Am J Physiol Endocrinol Metabolism 2000;279.

[30] Alsaif MA, Hakim IA, Harris RB, Alduwaihy M, Alrubeaan K, Alnuaim AR, et al. Prevalence and risk factors of obesity and overweight in adult Saudi population. Nutr Res 2002;22:1243-52. 